one of these birds with the muscles and integuments preserved.

Several portions of the external covering of the bird have also been discovered, along with bones, which show signs of recent interment. Beside feathers, the complete skeleton in the museum at York has the integument of the feet partly preserved, from which it is evident that the toes were covered with numerous small hexagonal scalcs. We are now able to supplement our knowledge with a description of the covering of the tarsus from a specimen sent by Dr. Haast to Prof. Alphonse MilneEdwards, which is to be seen in the Museum of Natural History at Paris. This specimen is figured, one-fourth the natural size, in the accompanying drawing, for which we have to thank the propristors of our enterprising French namesake La Nature. It was obtained at Knobly Range, Otago, and belongs to the species Dinornis ingens. From it we learn that the tarsus, as well as the toes, was nearly cntirely covered with small horny imbricate scales, and not with broad transverse scutes, as it might quite possibly have been. It is also evident that the hind toe, or hallux, waich is not present in either the Ostrich, Rea, Emu, Cassowary, nor in some species of Moas, was articulated to the metatarsal segment of the $\operatorname{limb}$ a little above the level of the other toes. Those species of Dinornis which possess the hind toe, Prof. Owen includes in the genus Palapteryx.

Amongst the struthious birds, the Hoas agree most with the Apteryx, in the presence (occasionally) of a fourth toe; and in their geographical distribution. They resemble the Cassowaries and the Emus most in the structure of their feathers; and in the structure of the skull differ from all to an extent which has made Prof. Huxley arrange then as a separate family of the Ratita. A knowledge of the anatomy of their perishable parts would be an invaluable assistance in the determination of their true afinities, but it is almost too much to hope that the material for such an investigation will ever present itself.

\section{THE RECENT STORMS IN THE ATLANTIC}

THIS subject has attracted the notice of the Neru York Herald, which, in an article on the $23 \mathrm{rd}$ January, remarks that "the successive gales appear to have been connected with the high barometer or polar airwaves which have recently swept across the northern part of the United Staies." Our contemporary says, moreover, that the last "great barometer fuctuation was followed by a storm centre which the weather reports recorded on the 19 th inst. as then moving eastward over the Gulf of St. Lawrence. . . . In fact, the lesson apparently deducible from the recent steamer detentions and ship disasters we had to record is, that the severest cyclones may be looked for as the sequel phenomena of the great winter areas of high barometer and intense cold; or, in other words, the rising glass should be studied by the seaman as carefully as the falling glass."

Certainly, there is some truth in this assertion; but our contemporary ignores the startling fact that at the very same moment we had in Europe low pressure, southern gales, and high temperature. On the $15^{\text {th }}$ a strong southwesterly gale was raging at Valentia. Evidently the danger is very great when a rising barometer in America is coupled with a falling barometer in Europe, or vice versa.

Unhappily, the Transatlantic Telegraph is not in use now for sending meteorological summaries between liurope and America. It is deeply to be regretted that the practice was discontinued, and we hope the recent disastrous gales will induce the nations on both sides of the great ocean to neglect no longer that useful channel of mutual information.

W. DE Fonvielle

\section{TIEE PAST AND FUTURE WORK OH GEOLOGY*}

N the 29 th uit. Prof. Prestwich, who, as our readers know, has succeeded the late Prof. Phillips in the chair of Geolozy at Oxford, gave his inaugural lecture in the Musetm of the University. He commenced by paying a high and well-merited tribute to the value of the work, the wide at tainments and character of his predecessor, Prof. Phillips, and giving a brief sketch of the aspect of geological science at the time the chair was established. Prof. Prestwich then proceeded to notice some of the larger features, whether on questions of theory or on questions of fact, by which the progress of geology has been marked, and which, while they may serve to show how much has been done, will yet indicate how much still remains to be accomplished.

"The geologist commences," Prof. Prestwich said, "where the astronomer ends. We have to adapt the large and broad generalisations of cosmical phenomena to the minuter details of terrestrial structure and constitution, which it is our business to study. The common origin of the solar system has been long inferred from the spheroidal figure of the earth and the relations of the planets to one another, and explained by evolution from an original nebulous mass; and geologists have had to consider how far such a hypothesis is in accordance with geological facts. The questions connected with the earliest stages of the earth's history are on the very boundary line of our science, but they have too important a bearing on its subsequent stages not to command our serious attention; and though obscure and theoretical, they serve to guide us to firmer ground. This nebular hypothesis has recently received from physicists corroboration of a most novel and striking character, equally interesting to geologisists and astronomers.

"The wonderful discoveries with respect to the solar atmosphere, made by means of the spectroscope, have now presented us with an entirely new class of evidence, which, taken in conjunction with the argument derived from figure and plan, gives irresistible weight to the theory of a common origin of the sun and its planets; and while serving to connect our earth with distant worlds, indicates as a corollary what of necessity must have been its early condition and probable constitution.

"The whole number of known elements composing the crust and atmosphere of the earth, the lecturer went on to say, amount only to sixty-four, and their relative distribution is vastly disproportionate. It has been estimated that oxygen in combination forms by weight one-half of the earth's crust; silicon enters for a quarter; tinen follow aluminium, calcium, marnesium, potassium, sodium, iron, and carbon. These nine together have been estimated to constitute consist of the remaining fifty-five non-metalic and metallic elemells.

"The researches of Kitchloff, Angströrn, Thalen, and Lockyer" have now made known, that of these sixty-four terrestrial elements there are twenty present in those parts of the solar atmosplicre called the "chromosphere" and "reversing layer," as the stratum which surrounds the photosphere is called from certain optical properties. They consist of $\mathrm{t}$ -

$\begin{array}{llll}\text { Aluminium. } & \text { Chromium. } & \text { Lead (?) } & \text { Sodium. } \\ \text { Barium. } & \text { Cobalt. } & \text { Magnesium. } & \text { Strontium. } \\ \text { Cadmium. } & \text { Copper (?) } & \text { Manganese. } & \text { Titanium. } \\ \text { Calcium. } & \text { Hydrogen. } & \text { Nickel. } & \text { Uranium. } \\ \text { Cerium. } & \text { Iron. } & \text { Potassium. } & \text { Zinc. }\end{array}$

“Nor, with possibly two exceptions, does the spectroscope give any indication of unknown elements.

"While these phenomena afford such strong aiditional proofs of the common origin of our solar system, Mr. Norman Lockyer, basing his inquiries upon these and other facts recently acquired

* Inaugural Lecture of J. Prestwich, F.R.S., Professor of Geology in the University of Uxford. Delivered Jamuary 20.

$t$ On analysing this list we find:-

a Permanent Gas .... ...

2 Metals of the Alkalies $\quad \ldots \quad \ldots$

ll the Metals of the Alkaline... Sodium.

3 Metals of the Zinc class ... ... Magnesium. Zinc. Cadminm. All the Metals of the Iron Class... Manganese. Cobalt. Chromiun. 2 Metals of the Tin class . . ... Tin. Tin. Titanium. I Metal of the Lead class (probabily)

The metals of the Tiunsten, Antimony, Silver, and Gold classes are entirely unrepresented, while, if we except the nietallic nature of hydrogen, there is not a single metalloid on the list, although they have been diligently searched for. 
on the constitution of the sun, has been led to form some views of singular interest bearing on the probable structure of the crust and nucleus of the earth. With his permission I am enabled to lay before you some of the points in the inquiry he is now pursuing.

"Observation and theory have both led him to the unexpected conclusion that in the case of an atmosphere of enormous height and cousisting of gases and of metallic elements in a gaseous state, gravity overcomes diffusion, and the various vapours extend to different heights, and so practically arrange themselves in layers; and that in the sun, where owing to the fierce solar temperature the elements exist in such a state of vapour and of complete dissociation, the known elements are observed to thin out in the main in the following order * :-

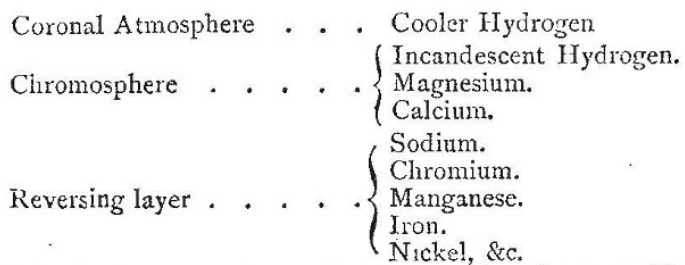

"Mr. Lockyer suggests, and has communicated some cvidence to the Royal Society in support of his suggestion, that the rnetalloids or non-metaliic elements as a group lie outside the metallic atmosphere. He also explains why under these conditions their record among the Fraunhofer lines should be a feeble one. Hence he considers that we have no argument against the presence of some quantity of the metalloids in the sun taken as a whule, although that quantity may be small.

"Mr. Lockyer then takes the observed facts together with the hypothesis of the external position of the metalloids, and is considering these two questions:-

1. Assuming the earth to have once been in the same condition as the sun now is, what would be the chemical constitution of its crust?

2. Assuming the solar nebula to have once existed as a nebulous star at a temperature of complete dissociation, what would be the chemical constitution of the planets thrown off as the nebulosity contracted?

"It will be seen that there is a most intimate connection be. tween these two inquiries; the localisation of the various elements and the reduction of temperature acting in the same way in botli cases.

"Thus to deal with the first question; as the external gaseous vapours (those of the metalloids) cooled they condensed and fell on the underlying layer, where they entered into combination, forminer one set of binary compounds, and then others as the temperature was reduced, until finally all the netals and earths were precipitated. +

"Ii now we turn to the earth's crust we find it very generally assumed that the fundamental igneous rocks which underlie the sedimentary strata, and which formed originaliy the onter layers, may be divicied into two great masses holding generally and on the whole a definite relation one to the otheran upper one consisting of granite and other Plutonic rocks, rich in silica, moderate in alumina, and poor in lime, iron, and magnesia ; and of a lower mass of basaltic and volcanic rocks of greater specific gravity, with silica in smaller proportions, alumina in equal, and iron, lime, and magnesia in

* Mr. Lockyer points"out that this order is that of the old atomic or combining weights, and not that of the modern atomic weights, as the followng table sliows :-

Hydrcgcn
Magnesium
Calcium
Sodium
Chromium
Manganese
Iron ...
Nickel ...

$$
\begin{aligned}
& \text { Old A tomic } \\
& \begin{array}{lc} 
& \text { Weights. } \\
\ldots . & x \\
\ldots . & 12 \\
\ldots . & 20 \\
\ldots . & 23 \\
\ldots . & 26 \\
\ldots . & 27 \\
\ldots & 28 \\
\ldots & 29
\end{array} \\
& \begin{array}{cc} 
& \\
\ldots . & \ldots \\
\ldots . & \ldots \\
\ldots . & \ldots \\
\ldots & \ldots \\
\ldots & \ldots \\
\ldots & \ldots \\
\ldots & \ldots \\
\ldots & \ldots
\end{array}
\end{aligned}
$$

\begin{tabular}{|c|c|c|}
\hline & \multicolumn{2}{|c|}{$\begin{array}{l}\text { New Atomic } \\
\text { Weights. }\end{array}$} \\
\hline ,.. & $\ldots$ & I \\
\hline$\ldots$ & $\ldots$ & 2.4 \\
\hline ... & $\ldots$ & 40 \\
\hline$\cdots$ & $\cdots$ & 23 \\
\hline$\ldots$ & $\ldots$ & 52.5 \\
\hline & $\ldots$ & $55^{\circ}$ \\
\hline & $\ldots$ & 56 \\
\hline & $\ldots$ & 58 \\
\hline
\end{tabular}

Aluminium does not find a place in the above list, because its order in the layers has not yet becn determined by observation, but the principle referred to would place it between maginesium and calcium.

+ Hirtly, those binary compounds capable of existing at a high temperature, such as the vapour of water, of hydrochloric acid, silica, carbonic acid, and others would be formed ; secondly, the precipitation of these would give rise to numerous reactions, forming a variety of silicates, chlorides, sulphates $\& c$. 1hirdly, with the condensation of watex the constitution of mineral would be effected, double decompositions would ensue, and the consolidation of the outer shcll commence. much larger proporbions, with also a great variety of other elements as occasional constituents; while the denser metals are in larger proportion in the more cen'ral portion of the nucleus. The suggestion of $\mathrm{Mr}$. Lockyer is that this order follows necessarily from the original localisation of the earths and metals Lefore referred to, by which the oxygen, silicon, and other metalloids formed, as they now do in the sun, an outer atmosphere, succeeded by an inner one consisting in greater part of the alkaline earths and alkalies, then by a lower one of iron and its associated group of metals, and fiaally by an inner nucleus containing the other and deoser metals.

"As we have beforc observed, above nine-tenths of the earth's crust consists of those elements which, on the assumption of the extermal position of the metalloids, would constitu:e the outer layers of the nebular mass. Thus, oxyen and silicon alone constitute on the average 5 of the mass of acid Plutonic rocks of which the upper part of the first assumed shell of the earth consists; while beneath it are the basic rocks, into the composition of which calcium, magnesium, and iron, combined with oxygen, enter in the proportion of, say, 155 , the silica being less by 123 still deeper lie the denser and harder metals, which reach the surface only through the veins transversing the outer layers.

"We vext come to the second question clealing with the cluemical constitution of the planets. It is imagined that the same consideration would hold good, and that the exterior plarets may approach in their constitution that of the sun's outer atmosphere, and that the planets may become more metallic as their orbits lie nearer the central portion of the nebula. Mr. Lockyer con. siders that the low density and gigantic and highly absorbing atmospheres of the outer planets accord with their being more metalloidai ; and that, on the other hand, the high density and comparatively small and feebly absorbing atmospheres of the inner planets, points to a more intimate relation with the inner layers of the original nebulous mass. For the same reason we should expect to find the metalloids scarcer in the sun than in the earth.

"In the Jovian system, and in our own moon, we have a still further support of the hypothesis in the fact that the density of the satellites is less than that of their primary.

"I had hoped," Prof. Prestwich contintred, "to have brought before you some of the results of the examination of the spectra of portions of the outer igneous rock crust of the earth, which Mr. Lockyer kindly undertook to compare with the solar spectrum, but, owing to the state of the weather, the investigation is not yet complete. It may, however, be stated that, as in the spectrum of the sun, so in the spectrd of the granite, greenstone, and lava already tested, no trace of metalloids is present, although oxygen and silicon are so largely present in these rocks.

"We can, however, still only look on these views as hypothetical, but they commend themselves to us by their simplicity and granrieur, and their high sugsestiveness for futme inquiry and research. They show us also how the spectroscope may, as the microscope has done already, aid the investigations of the geologist-the one by endowing the eye with new powers of sight with respect to the infunitely minute, and the other with new powers of tangible analysis with respect to the infunitcly distant.

"Quiting the early history of cur globe, we leave the domain of the astronomer and enter upon one shared by the geologist, the mineralogist, the chemist, and the mathematician. Instead of the sixty-four simple elements, their mutual reactions have resulied in the formation of somewhere about $I, 000$ varieties of rocks and minerals alone, with which the geolorist has in future to deal. He also has to deal with all the physical problems arising from the consolidation of the crust of the earth-from pressure due to gravitation and contraction-from the action of subterranean forces-from the effects of heat-and with all the varied phenomena resulting from these complex conditions."

Mr. Prestaich then referred to the early belief that the thickness of the crust of the earth does not now excced thirty to sixty miles; and to the conclusion, supported by Sir W. Thomson, of the late Mr. Hopkins, who, reasoning on phenomena connected with precession or nutation, concluded that on the contrary it could not be less than 800 miles thick or more.

Remarking that it is difficult, however, to reconcile thece views with the extent and character of modern volcanic action, Prof. Prestwich referred to the theories propounded by Mr. Mallet in his remarkable paper recently published in the Transactions of the Royal Society.

"In stratigraphical geology," the lecturer went on to say, "the great divisions originally marked out by our predecessors stand, 
but their number and the number of subdivisions have greatly increased. In I822, when Phillips and Conybeare wrote their 'Geology of England and Wales,' twenty-three so-called formations were recognised, whereas now thirty-eight such are established, and these are divided into about $\mathrm{I} 20$ subdivisions, each characterised by some peculiarity of structure or of fauna. Palæontology as a separate science was not then known; structural and physical geology had chiefly occupied attention; but the study of organic remains has since advanced with such rapid and vigorous strides that the older branch was until lately in danger of being neglected and distanced.

"At that time the number of species of organic remains in Great Britain which had been described amounted only to $75^{2}$, whereas now the number amounts to the large total of 13,276 species.

"Some idea of the extent and variety of the past life of our globe may he formed by comparing these figures with the numbers of plants and animals now living in Great Britain. Excluding those classes and families, such as the naked mollusca and others, which from their soft and gelatinous nature decay rapidly, and so escape fossilisation, and insects * the preservation of which is exceptional-the number of living species amounts to 3,989 , against $\mathrm{I}_{3}, 183$ extinct species of the same classes.

"'Thus, while the total number of those classes of vertebrate and invertebrate animals and plants represented in a fossil state, and now living in Great Britain, is only 3,989, there formerly lived in the same area as many as 13,276 species, so that the fossil exceed the recent by 9,287 species. It must be remembered also that plants are badly represented, for, owing to their restricted preservation, the fossil species only number 823 against 1,820 recent species. Birds are still worse represented, as only eighteen fossil species occur against 354 recent species.

"But the multiplicity of British fossils, however surprising as a whole, has to be viewed in another and different light. The large total represents, not as the recent species do, the life of one period, but the sum of those of all the geological periods. Geological periods, as we construct them, are necessarily arbitrary. The whole geological series consists of subdivisions, each one of which is marked by a certain number of characteristic species, but each having a large proportion of species common to the subdivisions above and below it. These various subdivisions are again massed into groups or stages, having certain features and certian species peculiar to them and common throughout, and which groups are separated from the groups above and below by greater breaks in the continuity of life and of stratification than mark the lesser divisions. As these on the whole severally exhibit a distinct fauna and flora, we may conveniently consider them as periods, each having its own distinctive life, and the number of which in Great Britain we have taken approximately at thirty-eight.

"The number of species common to one period and another varies very greatly, but taking the average of the sixteen divisions of the Jurassic and Cretaceous series, of which the lists were, with a portion of those of the older series, given a few years since by Prof. Ramsay, + we may assume that about thirty per cent. of the organic remains pass from one stage to another.

"Dividing the 13,276 fossil species among the thirty-eight stages, or omitting the lower stages and some others, and taking only thirty, we thus get an average of 442 species for each ; and, allowing in addition for the number common to every two periods, we obtain a mean of 630 species as the population of each of the thirty periods, against the 3,989 species of the present period. On this view the relative numbers are therefore reversed.

"This gives a ratio for the fauna or flora of a past to that of the present period of only as I : $6 \cdot 3$. But it must be remembered that probably the actual as well as the relative numbers of the several classes inter se in each and all of these several formations, varied greatly at the different geological periods. Still we have no reason to suppose but that during the greater part of them life of one form or another was as prolific, or nearly so, in the British area then as at the present day, and we may thus form some conception of how little relatively, though so much really, we have yet discovered, and of how much yet remains to be done before we can re-establish the old lands and seas of eachi successive period, with their full and significant populations, This we cannot hope ever to succeed in accomplishing fully, for

* The number of British species of insects amounts to between 10,000 and Ir,,$\infty$.

$\dagger$ Anniversary Addresses for 1863 and $x 864$. Quarterly Fournal Geologucal Socicty. The tables were computed by Mr. Etheridge. decay has been too quick and the rock entombment too much out of our reach ever to yield up all the varieties of past life ; but although the limits of the horizon may never be reached, the field may be vastly extended; each segment of that semicircle may yet be prolonged we know not how far; and it is in this extension-in the filling up of the blanks existing in the life ot each particular period--that lies one great work of the future."

(To be continued.)

\section{NOTES}

IT is perhaps too much yet to expect. any allusion to the interests of science in that very staccalo composition, a Queen's Speech. The next best thing to this, however, occurred last Friday, when Lord Rayleigh, the, seconder of the Address, very courageously pointed out the omission from the Speech of any allusion to an event "which had excited some public interest of a non-political character." His lordship referred to the recent Transit of Venus, in which the astronomers of this country had taken a part, but by no means, he thought, "too large a part." We confess that on this point we quite agree with Lord Rayleigh; indeed, we think he has stated the case, as against England in this matter, with remarkable mildness. But this is a mere detail compared with what followed. Lord Ray. leigh said " he could not pass from astronomy without expressing a hope that other sciences of equal philosophicalinterest and greater material importance might receive more Government recognition than had hitherto been accorded them. It was something of an anomaly that England, whose great prosperity was largely due to scientific invention, should be slow to encourage those whose discoveries were laying the foundations of future progress. It was said, he knew, that these things might he safely left to individual enterprise, but there were fields of investigation in which individuals were powerless. We hope that this emphatic advocacy of the claims of science on Government, by one who has had the honour of being selected to second the Address on the Queen's Speech, augurs favourably for the amount of attention these claims are likely to secure during the forthcoming session.

The words of Mr. Disraeli on Monday night with regard to University Reform are also very cheering to those who wish to see some decided action taken towards the thorough reform of our Universities. Mr. Disraeli's words were very strong, so strong incieed as to amounit to an assurance that Government really means to take into serious consideration this session the Report of the University Commission. "It is our opinion," the Prime Minister said, "that no Government can exist which for a moment maintains that the consideration of University Reform, and consequently legislation of some kind, will not form part of its duty." These words give out no uncertain sound. Mr. Disraeli said, moreover, that when the Report was presented at the end of last session, the Colleges were not assembled. It would be interesting to know whether the Colleges have yet met to consider the Report, and whether they are likely to act on this hint of the Premier and take some internal action-commence the work of reform from within, instead of waiting until they are driven to it by forces from without.

WE are able to give this week the first instalment of an abstract of Prof. Prestwich's lecture in the chair of Geology at Oxford. We have printed it in small type, in order to be able to give as much as possible of an address which, our readers will see, is likely to mark an important stage in the history of geological science. The address will shortly be published in a separate form.

THE Arctic Committee appointed by the Admiralty, having completed its work and sent in a final report, was dissolved last week. The Committee has got through much work in the way 